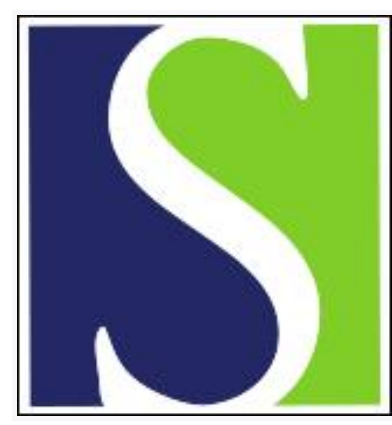

Scand J Work Environ Health 1990;16(4):278-283

https://doi.org/10.5271/sjweh.1784

Issue date: 01 Aug 1990

Moderate cold exposure in the Faroe fishing industry.

by Lundqvist GR, Jensen PL, Solberg HE, Davidsen E

Affiliation: Institute of Environmental and Occupational Medicine, Aarhus University, Denmark.

This article in PubMed: www.ncbi.nlm.nih.gov/pubmed/2389135 


\title{
Moderate cold exposure in the Faroe fishing industry
}

\author{
by Gunnar R Lundqvist, MSc, ${ }^{1}$ Preben L Jensen, BSc, ${ }^{1}$ Hans E Solberg, ${ }^{2}$ Eli Davidsen ${ }^{2}$
}

\begin{abstract}
LUNDQVIST GR, JENSEN PL, SOLBERG HE, DAVIDSEN E. Moderate cold exposure in the Faroe fishing industry. Scand J Work Environ Health 1990;16:278-83. Differences in female workers' finger temperatures, manual dexterity, ratings on thermal comfort, and local cooling exposure were studied in three factories in the Faroe Island fishing industry. Environmental temperatures in the factories varied from 5 to $19^{\circ} \mathrm{C}$ with vertical gradients of $7^{\circ} \mathrm{C} / \mathrm{m}$, and the mean temperatures of the flushing water varied from 2 to $15^{\circ} \mathrm{C}$. Finger temperature varied from 12 to $24^{\circ} \mathrm{C}$ when measured 2 min after work was stopped, and about one-third of the women experienced thermal discomfort in the fingers during work. The fish temperature increased, on the average, less than $1^{\circ} \mathrm{C}$ during passage through the production room, notwithstanding the thermal differences among the factories. These findings should be used in attempts to reduce the cold exposure of the workers; but also improved control should be recommended for both environmental and water temperatures in the factories.
\end{abstract}

Key terms: dexterity, finger temperature, fishing industry, rewarming, thermal comfort, water temperature.

The Faroe Islands have a large fishing industry that employs about 2200 workers of its total population of 47000 . In the indoor work environments of this industry the ambient air temperature may be as low as $5^{\circ} \mathrm{C}$, and exposure to cold is enforced by high air velocities, the wetness of clothing and skin surfaces, heat radiation to cold surfaces, and the handling of cool objects. Some authors have described such work conditions as moderate cold exposure when compared with cold exposure below the freezing point, and they have argued for attention to this kind of exposure in spite of no risk for frostbite or tissue damage $(1,2)$. The health problems of concern are discomfort, reduction of work capacity with related stress, and the possibility of higher accident rates. In addition, moderate cold exposure may be a cofactor in the development of chronic problems witiı muscles and joints.

The cold environment in the fishing industry is required to maintain the quality of the products, and the upper temperature limits are usually set by the veterinary inspection. However, precautions against cold exposure to the hands have recently been taken in some factories in that a higher water temperature and less flushing water are used during fillet cutting. The aim of our study was to investigate the extent to which workers differed in finger temperatures, finger dexterity, and subjective ratings on thermal comfort according to differences in the temperatures of the water used for flushing during the fillet cutting processes.

1 Institute of Environmental and Occupational Medicine, Aarhus University, Aarhus, Denmark.

2 Administration of Occupational Safety and Health, Torshavn, Faroe Islands.

Reprint requests to: Mr Eli Davidson, Arbeidseftirlitid, Postboks 1134, FR 110, Torshavn, Faroe Islands.

\section{Subjects and methods}

The subjects under study were 24 women employed in three of the largest of the 22 fish filleting factories on the Faroe Islands. All of the women volunteered to participate in a manual dexterity test and to have their skin temperature measured four times during half of a normal workday. The first measurement took place before work, the second and third measurement during workhours, and the fourth after $3 \mathrm{~h}$ of work.

Three study groups, each with eight subjects with the same age distribution [median 37 (interquartile range $25-49$, total range $19-57$ ) years] and duration of employment [median 5 (interquartile range 1-9.5, total range $0.5-25$ ) years], were assigned to three factories using different procedures to fillet fish. In factory A fish were cut in cold running water, the temperature of the water depending on the season (seasonal variations between 1 and $12^{\circ} \mathrm{C}$; on the day of measurement between 1.7 to $2.2^{\circ} \mathrm{C}$ ). In factory B fish were cut without running water, water occasionally being used for flushing the table with a handspray (seasonal variations in water temperature between 1 and $12^{\circ} \mathrm{C}$; on the day of measurement between 4.3 and $6.4^{\circ} \mathrm{C}$ ). In factory $\mathrm{C}$ fish were cut under lukewarm running water (variations normally between 5 to $20^{\circ} \mathrm{C}$, depending on the total waterflow; on the day of measurement between 5 and $25^{\circ} \mathrm{C}$ with an average of $\left.15^{\circ} \mathrm{C}\right)$.

In all three factories the type of fish to be handled was identical with a core and surface temperature of below $5^{\circ} \mathrm{C}$. The amount of fish handled hourly by each worker was between 16 to $49 \mathrm{~kg}$ [median 33.5 (interquartile range $26-42) \mathrm{kg}$, depending on individual capacity and routine]. In estimating the efficiency of the production, we included not only the total weight, but also the waste. The quality of the work was supposed to be at the same level in all three factories, which en- 
sured that the fillets were visually inspected and free of any maggots or fish pins. Therefore the workers used their bare hands for optimized sensitivity instead of wearing protective gloves.

The air temperatures of the workrooms were measured with an MTM 20 recorder (Mitec, Sweden) simultaneously in three positions (at floor level, $1.7 \mathrm{~m}$ above the floor centrally in the workroom, and $1.7 \mathrm{~m}$ above the floor close to a wall facing the outside) for the determination of horizontal and vertical temperature gradients. Water temperature was recorded in the first position at the nearest worktable. The instrument in use gave four continuous temperature graphs, and for each of them the average, minimum, and maximum values and the time of their occurrence. Globe temperatures at the individual workplaces were not measured because of a lack of instrumentation.

The temperature of the fish fillets was measured with a sensor placed on the surface. The average weight of the fillets was $800 \mathrm{~g}$, and each packing case contained an average of $15 \mathrm{~kg}$ with a heat capacity of about $4 \mathrm{~kJ} / \mathrm{kg} \cdot{ }^{\circ} \mathrm{C}$.

The finger temperature of each hand was measured with the thumb and forefinger pressed against the thermocouple junction of a copper-constantan wire.

A pegboard test was used to measure manual dexterity because it is the most sensitive with respect to the simplicity required for field use (3). The pegboard had 100 holes $6 \mathrm{~mm}$ in diameter $25 \mathrm{~mm}$ apart in a square pattern. Each hole had to be filled with three pins, and working with both hands was allowed. The subjects were told not to take more than three pins in each hand at the same time. The number of losses of pins under the rotation between the thumb and the forefinger was counted, along with the time for completing the task. For each subject the results of the first trial were used as a base-line value, and later values were expressed in proportion to it.

The skin temperature of the forehead and the fingers of both hands was measured before and after the women performed the task, and their perceived thermal status was recorded on a seven-point rating scale for both the fingers and the whole body. The divisions of the scale were very cold $(-3)$, cold $(-2)$, somewhat cold $(-1)$, neither warm or cold $(0)$, somewhat warm $(+1)$, warm $(+2)$, and very warm $(+3)$.

Ratings of $-3,-2,+2$, and +3 were considered potential signs of thermal discomfort, while $-1,0$, and +1 were considered to be within tolerable limits. The clothing insulation of the women in the three factories was estimated to vary between 0.8 and $1.3 \mathrm{clo}$, and their work activity, standing in front of the filleting tables, equaled about $250 \mathrm{~W}$.

The experimental setup was located in a room or a corridor adjacent to the production hall in all three factories. The time needed to leave the production line and enter the measuring site was $2 \mathrm{~min}$, and the total time spent at the measuring site did not exceed $10 \mathrm{~min}$. The globe temperature for the measuring site was be- tween 16 and $18^{\circ} \mathrm{C}$ in the three factories, and the air velocity was less than $30 \mathrm{~cm} / \mathrm{s}$.

Each subject practiced the pegboard test and the experimental procedure several times the day before the actual test and under the same conditions in order to ensure sufficient instruction and to eliminate any training effect. Performance tests of this simple type are known to be sensitive to training effects and to the thermal conditions at the time of the training (4). However, the subjects in this study were skilled and accustomed to manual work. Therefore we considered one day of training enough to ensure an equal level of test performance for the three factory groups.

\section{Statistics}

The differences between the trials during the day were evaluated for each individual with Wilcoxons's test for paired data. The differences between the groups were tested by a one-way analysis of variance by ranks with the Kruskal-Wallis test, and associations between the variables were tested with the Spearman rank correlation test. A computer program (5) was used to perform the calculations.

\section{Results}

\section{Environmental measurements}

The air temperatures measured centrally $1.7 \mathrm{~m}$ above the floor ranged between 16 and $19^{\circ} \mathrm{C}$ in factory $\mathrm{A}$, between 12 and $16^{\circ} \mathrm{C}$ in factory $\mathrm{B}$, and between 11 and $17^{\circ} \mathrm{C}$ in factory $\mathrm{C}$, negative gradients to the floor and the outer walls fluctuating between 6 to $11^{\circ} \mathrm{C}$. The operative temperature would have been lower than the mean air temperature because of the influence of surfaces with lower temperatures around the workplaces. The air velocity ranged between 0.3 and $0.7 \mathrm{~m} / \mathrm{s}$, and the relative humidity between 50 to $70 \%$ in all the factories. Most of the horizontal surfaces were wet and therefore were cooled by evaporation.

\section{Skin temperatures}

The finger temperatures measured during workhours before the manual dexterity test did not differ between the groups because of the large variation among the individuals (the mean finger temperatures ranging between 19.5 and $20^{\circ} \mathrm{C}$ for factory $\mathrm{A}$, between 18.1 and $19.9^{\circ} \mathrm{C}$ for factory $\mathrm{B}$, and between 18.9 and $19.7^{\circ} \mathrm{C}$ for factory $\mathrm{C}$ ). Therefore, the finger temperatures of the workers in all three factories have been pooled for the observation of differences between trials and for the determination of total variation (table 1).

After the beginning of work the average finger temperature decreased significantly by $7^{\circ} \mathrm{C}(\mathrm{P}<0.005)$, whereas the temperature decrease from a mean of 19.7 to $19.1^{\circ} \mathrm{C}$ during the following $3 \mathrm{~h}$ was not significant but only indicated a trend $(0.05<\mathrm{P}<0.10)$. The finger temperatures of the left hand were about $0.5^{\circ} \mathrm{C}$ 
lower than those of the right hand. The explanation could be the dominant use of the left hand to handle the cold fillets and the right hand to handle the knife.

A rewarming of the finger surfaces took place immediately after the women stopped working, and recovery to the initial status was almost complete within 5 to $10 \mathrm{~min}(\mathrm{P}<0.005)$ among the workers from factories $\mathrm{A}$ and $\mathrm{B}$. In factory $\mathrm{C}$ the rewarming of the workers' fingers was, on the average, slower in all the trials (figure 1).

The temperature increase of the forehead in trials 1,2 , and 3 was also significant $(\mathrm{P}<0.05)$ (figure 1 ).

Table 1. Finger temperatures (average of left and right thumbs and forefinger) as measured before and after the manual dexterity test administered before work (trial 0 ) and after $1 \mathrm{~h}$ of work (trial 2), $2 \mathrm{~h}$ of work (trial 3), and $3 \mathrm{~h}$ of work (trial 4).

\begin{tabular}{lcccc}
\hline & \multicolumn{4}{c}{ Finger temperature ${ }^{\circ} \mathrm{C}$} \\
\cline { 2 - 5 } & Mean & Range & SD & SEM \\
\cline { 2 - 5 } Trial $0(\mathrm{~N}=48)$ & & & & \\
$\quad$ Before & 26.7 & $18.7-33.9$ & 4.7 & 0.9 \\
$\quad$ After & 26.5 & $19.2-34.2$ & 4.5 & 0.9 \\
Trial. 1 $(\mathrm{N}=48)$ & & & & \\
$\quad$ Before & 19.7 & $12.1-25.9$ & 2.7 & 0.9 \\
$\quad$ After & 25.2 & $17.4-32.3$ & 4.1 & 0.9 \\
Trial 2 $(\mathrm{N}=46)$ & & & & \\
$\quad$ Before & 19.1 & $13.8-24.5$ & 4.5 & 0.5 \\
$\quad$ After & 24.6 & $18.2-31.8$ & 4.2 & 0.8 \\
Trial 3 $(\mathrm{N}=48)$ & & & & \\
$\quad$ Before & & & & \\
$\quad$ After & 19.1 & $12.5-27.1$ & 2.9 & 0.6 \\
\hline
\end{tabular}

The workers' forehead temperatures before work and in the following hours before and after the manual dexterity test are shown in table 2 . The range between the lowest and the highest values of approximately $6^{\circ} \mathrm{C}$ (between 25.9 and $31.8^{\circ} \mathrm{C}$ ) in the same run should be noticed. The mean forehead temperature was $30.9(\text { SD } 1.9)^{\circ} \mathrm{C}$ before work and 30.4 (SD 1.8$)^{\circ} \mathrm{C}$ after $3 \mathrm{~h}$ of work $(\mathrm{P}>0.15)$. A difference was found between the factory groups before the test, the mean forehead temperature being higher in factory $\mathrm{A}\left(32.0^{\circ} \mathrm{C}\right)$ than in factories $\mathrm{B}$ and $\mathrm{C}\left(29.8^{\circ} \mathrm{C}\right)(\mathrm{P}<0.01)$. This difference reflected the higher room temperature measured in factory $A$.

Table 2. Forehead temperatures as measured before and after the manual dexterity test administered before work (trial 0 ) and after $1 \mathrm{~h}$ of work (trial 2), $2 \mathrm{~h}$ of work (trial 3), and $3 \mathrm{~h}$ of work (trial 4).

\begin{tabular}{llccc}
\hline & \multicolumn{4}{c}{ Forehead temperature ${ }^{\circ} \mathrm{C}$} \\
\cline { 2 - 5 } & Mean & Range & SD & SEM \\
\cline { 2 - 5 } & & & & \\
Trial 0 $(\mathrm{N}=24)$ & 30.9 & $26.8-33.6$ & 1.9 & 0.4 \\
$\quad$ Before & 32.0 & $28.9-33.5$ & 1.4 & 0.3 \\
$\quad$ After & & & & \\
Trial 1 $(\mathrm{N}=24)$ & 30.7 & $28.5-33.0$ & 1.2 & 0.3 \\
$\quad$ Before & 31.9 & $30.0-34.2$ & 1.2 & 0.3 \\
$\quad$ After & & & & \\
Trial 2 $(\mathrm{N}=23)$ & 30.3 & $25.9-31.8$ & 1.3 & 0.3 \\
$\quad$ Before & 32.0 & $30.1-33.6$ & 1.1 & 0.2 \\
$\quad$ After & & & & \\
Trial 3 $(\mathrm{N}=24)$ & 30.4 & $26.4-33.3$ & 1.8 & 0.3 \\
$\quad$ Before & 31.7 & $27.6-34.3$ & 1.6 & 0.3 \\
$\quad$ After & & & & \\
\hline
\end{tabular}
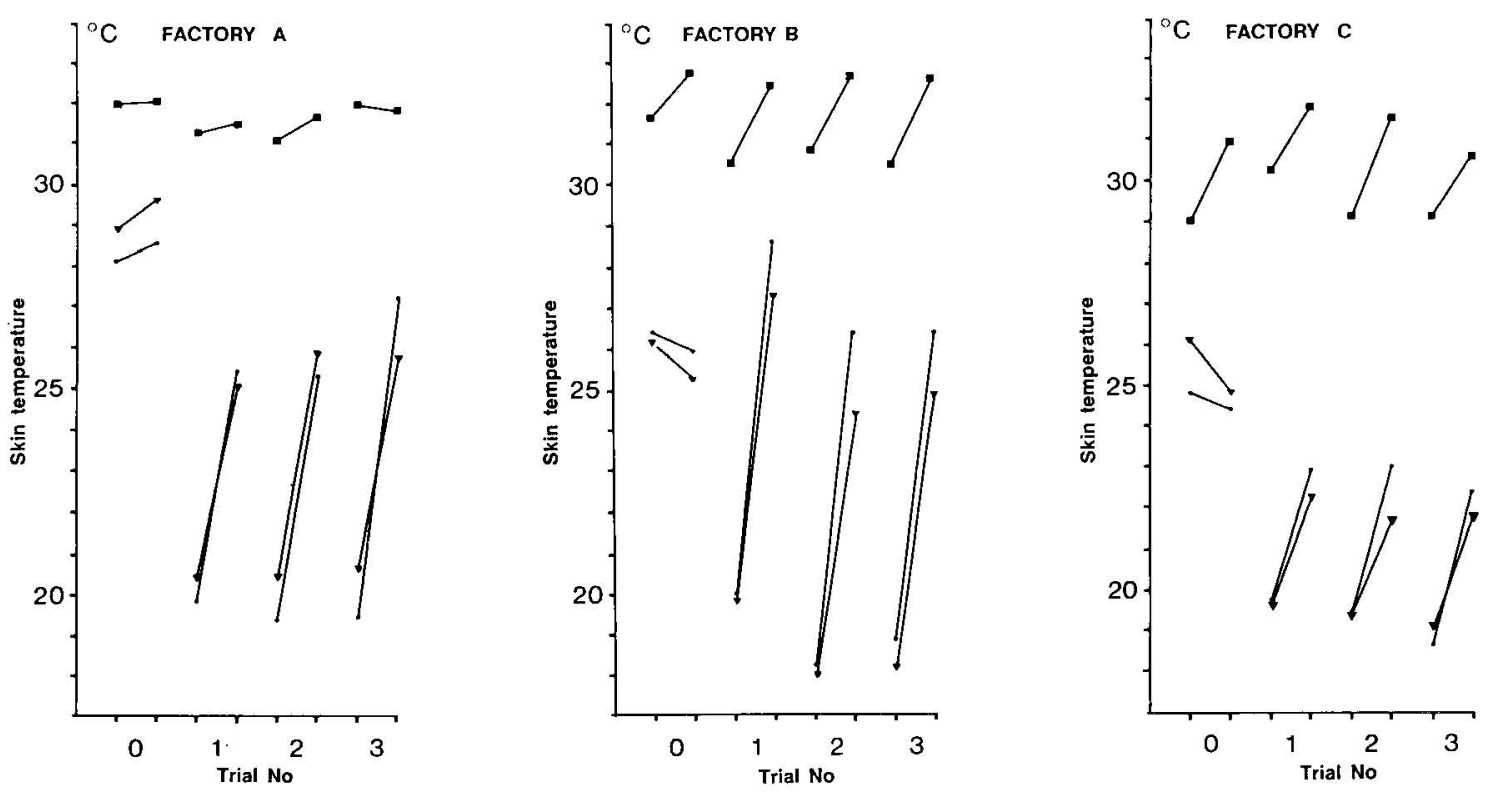

Figure 1. Changes in skin temperature before and after the manual dexterity test (interval time between measurements approximately 5 to $7 \mathrm{~min}$ ) in trials 0 (before work), 1, 2, and 3 (after 1,2 and $3 \mathrm{~h}$ of work, respectively) among the workers in factories $A, B$, and $C$. (Squares = forehead, triangles $=$ right hand, dots = left hand) 


\section{Thermal sensation}

In all three factories the thermal sensation showed individual variation during the workday, but an increase in cold sensation was indicated for the fingers after work began. This change was equal to a mean difference of 1.5 points on the scale, the rating moving from 0 (neutral) to between 1 (somewhat cold) and -2 (cold) $(P<0.005)$. Thermal sensation for the whole body was, on the average, between 0 (neutral) to +1 (somewhat warm) in factory A and between - 1 (somewhat cold) to 0 (neutral) in factories $B$ and $C$, with no trend from hour to hour. The differences in the individual ratings, ranging from -2 (cold) to +2 (warm) for the whole body and from -3 (very cold) to +2 (warm) for the fingers, was notable in one of the measuring sequences.

The rewarming that appeared in the measurements of the skin temperature of the fingers before and after the manual dexterity test was also apparent in the thermal rating (figure 2). The ratings of -2 (cold) and -3 (very cold) decreased, and the sensation of cold fingers changed by about two points on the scale in the warm direction within less than $10 \mathrm{~min}(\mathrm{P}<0.001)$.

The finger temperatures correlated with the subjective ratings on the thermal scale. Workers having finger temperatures below $19.5^{\circ} \mathrm{C}$ in all periods expressed distinctly more thermal discomfort than the other workers $(\mathrm{P}<0.05)$.

\section{Performance on the manual dexterity test}

The median score in the manual dexterity test was $\mathbf{3 3 0}$ (interquartile range 306-355) $\mathrm{s}$ in the test run before the beginning of work and 315 (interquartile range 294-355) s after $3 \mathrm{~h}$ of work. However, this difference and the differences between the groups were not significant because of the variation between the workers within the groups $(0.05<P<0.10)$. The number of errors due to the loss of pins was found to be less than $5 \%$ after the initial training and could not be used as a more sensitive element of the test. No correlation was found between the score of the manual dexterity test and the production level in kilograms per hour reported for the workers in the factory records. The individual scores of the dexterity test are shown in figure 3 in both absolute and relative units. It can be seen that, in the four trials, the interindividual variation was greater in both measures than the intraindividual variation.

\section{Fish temperature}

During the average 1-h transfer time in the workroom the temperatures on the surfaces of the fish fillets increased about 1 to $1.5^{\circ} \mathrm{C}$, while the core temperature did not change. The most critical period for temperature increase was during the $1-\mathrm{h}$ lunchbreak, during which the fish had a prolonged transfer time in the workroom. However, the surface temperature of the fillets did not raise above $7^{\circ} \mathrm{C}$. No differences in the core temperatures of the fish were found between the factories despite the differences in water and environmental temperatures.

\section{Discussion}

Local hand cooling, finger temperatures, thermal sensation, and pain have been examined in several studies focusing on either extreme or moderate cold conditions. One experiment using a hand cooling box showed that unadapted persons begin to experience cold at finger temperatures of about $28^{\circ} \mathrm{C}(6)$. In addition they reported pain below $20^{\circ} \mathrm{C}$ and distinctly experienced it below $16^{\circ} \mathrm{C}$ (6). However, daily or repeated immersion in cold or warm water will reduce the skin response, pain sensation, and impact on performance (7-9) . A subjective scaling of pain was con-
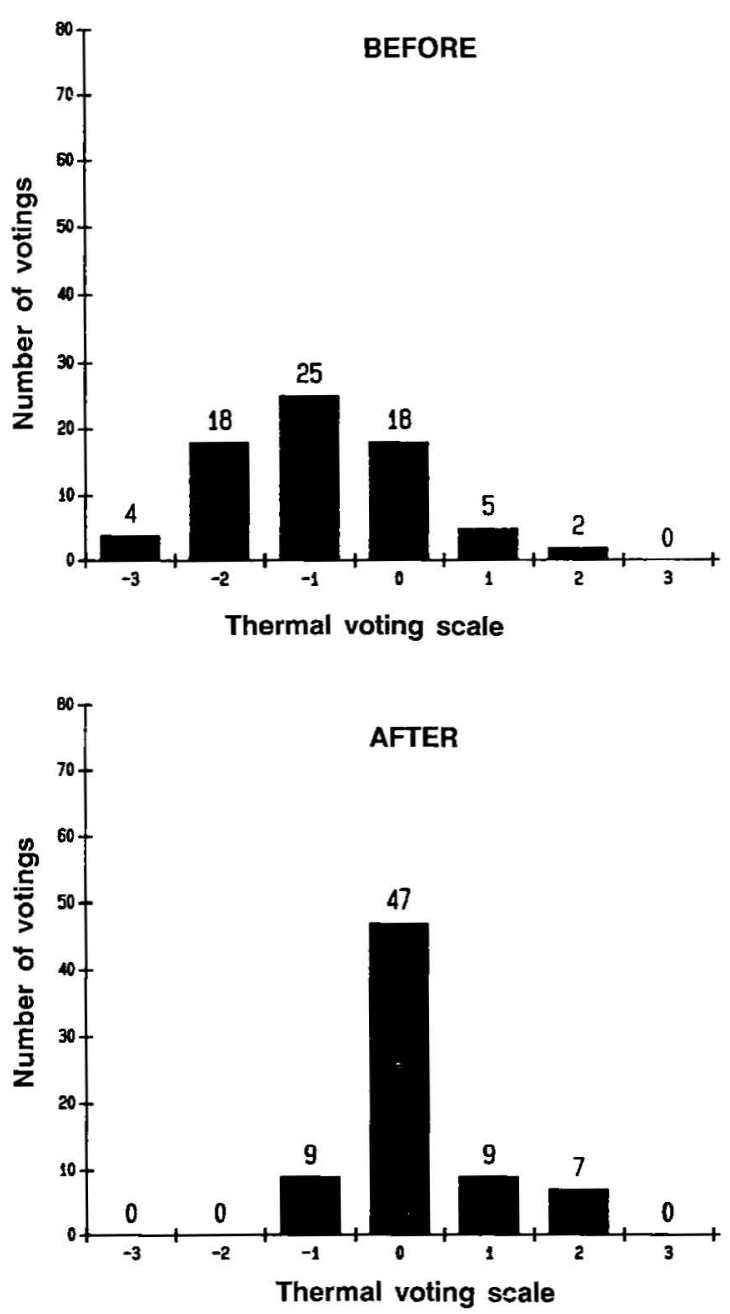

Figure 2. Changes in thermal sensation in the fingers as seen in ratings (votings) before (upper figure) and after (lower figure) rewarming during the manual dexterity test in trials 1,2, and 3 (after 1, 2, and $3 \mathrm{~h}$ of work) with the data of the three factory groups pooled. The thermal seven-point scale has been described in the text. 

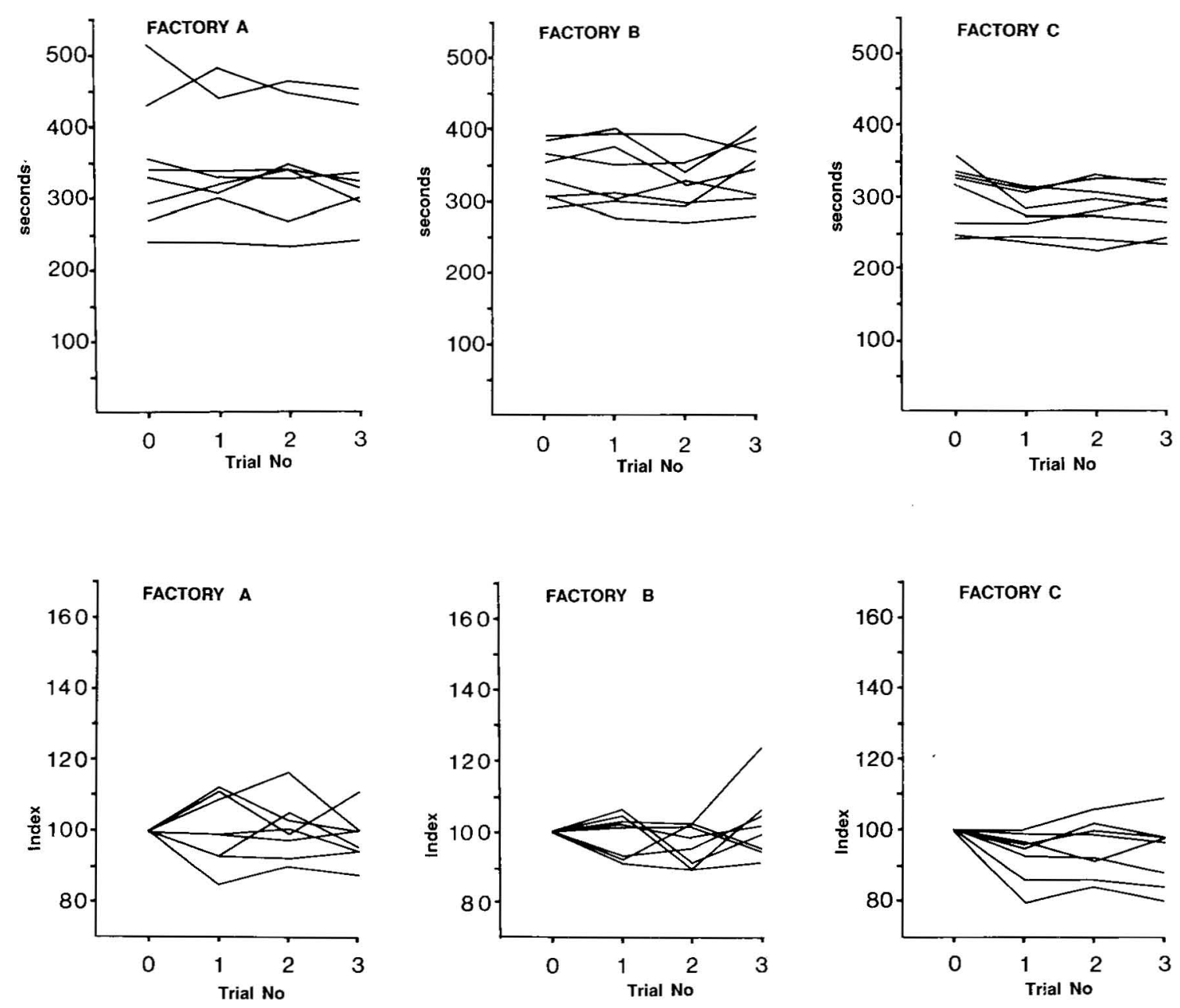

Figure 3. Absolute scores (upper figures), ie, seconds used for completing the test and relative scores (lower figures), ie, the determined index (seconds used in trial $0=100$ ), for the manual dexterity test (each line representing an individual) in trials 0 (before work), 1, 2, and 3 (after 1, 2, and $3 \mathrm{~h}$ of work, respectively).

sidered to be out of the scope of this study because we anticipated that workers with a daily routine work would not experience this work as painful in a normal sense.

It has been shown that the duration of vasoconstriction and the magnitude of cold vasodilation in hands immersed in ice-cold water is significantly different in fish filleters than in inexperienced referents (10). A higher skin temperature among the filleters and a faster onset and magnitude of both vasoconstriction and vasodilation was attributed to acclimatization. Such physiological phenomena among workers in the fishing industry long enough to reach different levels of acclimatization could also be one explanation for the large interindividual variations and minute-to-minute changes in finger temperatures that were found in our study.

Our measurements showed, in particular, the ability of the blood vessels in the finger to respond immediately to changes in thermal conditions and work load. The woman with the lowest finger temperature $\left(12^{\circ} \mathrm{C}\right)$ when coming from the work process in factory A displayed a $12.5^{\circ} \mathrm{C}$ increase to $24.5^{\circ} \mathrm{C}$ within the about $6 \mathrm{~min}$ that she worked at the pegboard, whose pins had temperatures of $16-18^{\circ} \mathrm{C}$. The finger temperatures were always measured about 2 min after the worker interrupted her fillet cutting and moved to the adjacent room. Therefore all the measurements were comparable, but they overestimate the finger temperatures at the place of work by approximately $2^{\circ} \mathrm{C}$. This overestimation could be a point of criticism with respect to the experimental arrangement.

The differences in the work processes in terms of water temperature and the use of running water did not correlate with the differences in the finger temperatures or the variations in the tested finger dexterity. The large interindividual variation and the counteracting and fluctuating thermal conditions within the factories could have been responsible for this lack of correlation. The influence of the differences in the 
flushing method on skin wetness was not recorded, but should have been.

The demonstration of the negligible impact of the room and water temperatures on the core temperature of the fish turned out therefore to be the most important result to be applied in a discussion of changes in the thermal work conditions of fish processing plants.

Several questionnaire studies have shown a high prevalence of complaints of work-related discomfort from both male and female workers in the fishing industry in some of the Nordic countries (Denmark, Faroe Islands, Iceland, and Norway) with averages of about 50 to $70 \%$ of the employees complaining of the cold and wet environmental exposure in the standing position with only minimal whole-body movements. In comparison, the whole-body thermal comfort of the workers in our study was surprisingly good, if only the average scores of the subjective ratings are considered. However, the averages were balanced by ratings on both the cold and the warm sides of the scale. This finding emphasizes the fact that the thermal conditions of large rooms can show large variations. Therefore the thermal conditions have to be examined at each workplace several times during the day, and this examination should be supplemented with the recording of physiological indices of thermal balance among the subjects $(11-13)$. Access to such data should also be required for standardized calculations of the predicted mean vote for thermal discomfort at the various worksites.

In all three factories we found vertical temperature gradients that were much higher than the labor inspectorate's recommendation of $1.5^{\circ} \mathrm{C} / \mathrm{m}$ from floor to ceiling. There were also temperatures at floor level that were lower than the recommended $10^{\circ} \mathrm{C}$. Moreover, operative temperatures should be measured at several workplaces that are representative distances from cold wall surfaces or cold storage areas because substantial differences in the workrooms have to be expected.

Precautions against temperature gradients, draft, and large areas with wet surfaces that create evaporative cooling in the workrooms, and a more elaborate control of both water and environmental thermal conditions should be applied to obtain improvements. In our study the fluctuations in water temperature in factory $\mathrm{C}$, where lukewarm water was supposed to be used, may be one of the reasons for the failure in this study to prove the benefits of flushing with lukewarm water in comparison with flushing with cold water.

In addition to the moderate cold stress in the fishing industry, cases of itching, redness, and smarting of the skin, particularly on the forearms, the face, and the back of the hands, have been observed in relation to certain types of fish, the condition of the fish, and the season (14). However, the same authors observed an almost complete absence of symptoms on fingers and palms, and they supposed this absence was caused by these skin surfaces being protected by the cold run- ning water. This result may illustrate the need to integrate the knowledge of other phases of occupational medicine into the process of developing preventive measures for this industry.

Length of employment in the factories did not correlate with the age of the employees in our study, and this finding may indicate a high turnover rate for the work force. On the other hand, productivity correlated with length of employment ( $>3$ years), and this finding should indicate the advantage of less replacement for the factories. When asking about the high turnover rate, we found it to be explained by the uncomfortable work conditions in comparison with the work conditions of other jobs. This difference should also be an impetus to improve the work conditions found in the fishing industry.

\section{References}

1. Enander A. Sensory reactions and performance in moderate cold. Stockholm: Arbetarskyddsverket, 1986: 1-43. (Arbete och hälsa; 32.)

2. Enander A, Ljungberg A-S, Holmér I. Effects of work in cold stores on man. Scand J Work Environ Health 1979;5:195-204.

3. Lockhart JM, Kiess HO. Auxiliary heating of the hands during cold exposure and manual performance. Hum Factors 1971;13:457-65.

4. Clark RE, Jones CE. Manual performance during cold exposure as a function of practice level and the thermal conditions of training. J Appl Psychol 1962;46(4): $276-80$.

5. Wulff HR, Schlichting P. Guide to MEDSTAT version 2.1: statistical program for the analysis of the results of controlled therapeutic trials and other types of clinical research. Albertslund (Denmark): Astra, 1988.

6. Enander A. Perception of hand cooling during local cold air exposure at three different temperatures. Ergonomics $1982 ; 25: 351-61$.

7. Adams T, Smith RE. Effect of chronic local cold exposure on finger temperature responses. J Appl Physiol 1962;17(2):317-22.

8. Eide R. The relationship of pain sensation to cold pressor reactions and local cold habituation. Scand $\mathbf{J}$ Clin Lab Invest 1965;17:584-8.

9. Enander A, Sköldström B, Holmér I. Reactions to hand cooling in workers occupationally exposed to cold. Scand J Work Environ Health 1980;6:58-65.

10. Nelms JD, Soper DJG. Cold vasodilation and cold acclimatization in the hands of British fish filleters. J Appl Physiol 1962;17(3):448-48.

11. Nielsen $R$, Nielsen $B$. Influence of skin temperature distribution on thermal sensation in a cool environment. Eur J Appl Physiol 1984;53:225-30.

12. Nielsen R, Nielsen B. Measurement of mean skin temperature of clothed persons on cool environments. Eur J Appl Physiol 1984;53:231-6.

13. Nielsen R. Clothing and thermal environments: field studies on industrial work in cool conditions. Appl Ergon 1986;17:47-57.

14. Halkier-Sørensen L, Thestrup-Pedersen K. Skin complaints in the fish industry. Ugeskr Laeger 1988;150: 1792-4.

Received for publication: 18 August 1989 